\title{
Does Social Capital Affect Entrepreneurial Intentions?
}

\author{
Francisco Liñán • Francisco Javier Santos
}

Published online: 9 September 2007

(C) International Atlantic Economic Society 2007

\begin{abstract}
Nowadays, the scientific community assigns both social context and entrepreneurs' behavior as a central role in the growth and development of the world economy. However, the relationships between these two factors have not been sufficiently studied in business and economics. Therefore, in this paper, the specific influence of the new socioeconomic factor of social capital on the formation of entrepreneurial intentions will be analyzed. To test the theoretical hypotheses, an empirical study will be carried out using the Partial Least Squares (PLS) technique with data from a sample of young undergraduate students in the last year of their degree. This population has been selected because these individuals, according to different studies, show a higher propensity towards firm creation.
\end{abstract}

Keywords Entrepreneurship - Entrepreneurial intention · Social capital

JEL $\mathrm{M} 00 \cdot \mathrm{Z} 13$

\section{Introduction}

Entrepreneurship theory has substantially advanced during the past 30 years. The main reason is the central role nowadays assigned to human capital and entrepreneurs by the scientific community in the growth of the different regions of the world economy (Wennekers and Thurik 1999; Audretsch and Thurik 2000; Galindo and Alvarez 2004). From an empirical point of view, that important role of

A previous version of this paper was presented to the 61st International Atlantic Economic Conference held in Berlin (15-19, March 2006).

F. Liñán · F. J. Santos $(\bowtie)$

Department of Applied Economics I, Facultad de Economicas y Empresariales, University of Seville (Spain), Av. Ramón y Cajal, 1, 41018 Seville, Spain

e-mail: fjsantos@us.es

F. Liñán

e-mail: flinan@us.es 
the entrepreneur is related to the large changes that have taken place in recent decades, such as the fast pace of technological development and the growing globalization process derived from the liberalization of markets and from the transition of ex-communist countries to capitalism. In this context, the need for greater creativity and entrepreneurial capacities has increased.

The different fields of study within the entrepreneurship research program have recently focused both on the analysis of the characteristics of existing entrepreneurs and their quality (Davidsson 1991; Lumpkin and Dess 1996; Santos and Guzmán 2001), and also on the analysis of the characteristics of potential entrepreneurs and the firm-creation process (Krueger and Carsrud 1993; Reynolds et al. 1999; Liñán 2004). This paper identifies with this second field of research.

The analysis starts from Ajzen's theory of planned behavior, which has been used by Krueger and Carsrud (1993) to build their entrepreneurial intention model. Our main objective, then, is to introduce within this intention model the new socioeconomic concept of social capital (Lin 2003) to study its influence on the configuration of intentions and, subsequently, on the individual's firm-creation potential. The main reason to consider social capital in this study is the important role that nowadays, it is also assigned to social relationships and cooperation for economic success, both at a macro level (society) (Putnam 1993) and at a meso or micro level (firm and individual; Fukuyama 1995; Barros and Alves 2003).

To test the theoretical hypotheses, an empirical study will be carried out using Partial Least Squares as a statistical technique. Our data come from a sample of young last-year undergraduate students. This population has been selected on the basis of its high propensity to start a venture (Krueger et al. 2000).

After this introduction, the paper is organized in three sections. First, the theory regarding entrepreneurial intention models and the concept of social capital and its characteristics and typology are discussed. Social capital is then introduced into the entrepreneurial intention model, leading to the establishment of several hypotheses to be tested throughout the empirical analysis. Second, the empirical analysis will be performed, including data used, methodology and main results. The paper finishes with a discussion of those results and their implications.

\section{Theoretical Background}

\section{Entrepreneurial Intention Models}

A large number of studies on qualitative aspects of entrepreneurs have focused on the psychological characteristics and personality traits which differentiate both successful entrepreneur from non-successful entrepreneurs, and entrepreneurs from the rest of the population (Borland 1975). Later studies have emphasized the importance of different demographic factors, such as age, gender, religion, ethnic group, education, family, socioeconomic status, and professional experience (Reynolds et al. 1994).

Both research studies have made possible the identification of some significant relationships between several traits and demographic factors of individuals, on the one hand, and the fulfillment of entrepreneurial behaviors on the other hand. 
Nevertheless, from a theoretical point of view, both approaches have been criticized due to their methodological and conceptual problems, and also for their low explanatory capacity (Krueger et al. 2000). In fact, according to Chell (1986), accepting these approaches would mean that nobody can learn to be an entrepreneur.

Later on, starting from the theory of social learning developed by Bandura (1977), an important approach emerges to explain the entrepreneurial behavior: the entrepreneurial intention models. The central factor of this approach is the individual's intention to undertake a specific behavior (Shapero and Sokol 1982; Krueger and Carsrud 1993). Intentions capture the motivational factors which influence behavior, indicating the effort the individual plans to exert to put this behavior into practice. So, the higher the intention to undertake the behavior, the higher the probability of its performance will be.

An important early contribution within this approach is the theory of the "entrepreneurial event" (Shapero and Sokol 1982). According to this theory, individuals decide to create a firm (develop their intentions and become potential entrepreneurs) when a precipitating event lets them perceive the entrepreneurial activity as more desirable or more feasible than other alternatives. Specifically, according to Shapero and Sokol's model, intentions are established based on two perceptions:

- Perceived desirability: This measures the degree of attraction an individual perceives towards a specific behavior, such as becoming an entrepreneur.

- Perceived feasibility: This is defined as the perception regarding their own capacity to carry out a specific behavior (becoming an entrepreneur).

Similarly, but in greater detail, Ajzen (1991) develops the so-called theory of "planned behavior." According to this, intentions to perform a specific behavior directly depend on three perceptions. The first two-personal attraction and perceived behavioral control or self-efficacy - are quite similar to those of Shapero and Sokol, which are perceived desirability and perceived feasibility. The third one refers to "social norms" or the perceived social pressure to perform a behavior. That is, if individuals perceive that other people in their personal environment would agree to perform the behavior, this will contribute to a more favorable intention towards the performance of that behavior.

Nevertheless, there may be one reason to question the location of social norms within that intention model. According to Ajzen (1991), 11 out of 19 empirical studies testing the theory of planned behaviour found that the regression coefficient for the variable "social norms" were negative or non-significant to explain directly on intentions. In our opinion, this may be due to social norms exerting their influence directly on perceived desirability and on perceived feasibility and only then, indirectly, on intention.

On the other hand, there also may be one reason to pose a reformulation of Ajzen's intention model. It is known that human capital is very important in the formation of human cognitive abilities (Becker 1964), where perceived feasibility and desirability would be included. However, according to Coleman (1988), social relationships are a highly relevant element in the creation of this human capital. Then, the inclusion of different constructs representing the social relationships of the individual (not only social norms) would seem to be a relevant way to improve the 
explanatory capacity of intention-based models. To do so, it also may be necessary to review the socioeconomic concept of social capital.

Social Capital in the Model of Entrepreneurial Intentions

Social capital is made up of the relationships, either formal or informal, generated by individuals in their interaction with other individuals trying to obtain an expected reward in the market. That is, social capital could be defined as capital captured in the form of social relationships (Lin 2003).

Social capital results from a process of investment in human relationships, which requires resources and, more specifically, time (Lin 2003). Besides, social capital makes it easier to access information, reduce transaction costs by allowing the coordination of activities, and, finally, facilitate collective decision-making (Grootaert and van Bastelaer 2001). Also, as indicated above, it allows access to other forms of capital, such as human capital (Coleman 1988). Likewise, social capital, the same as physical capital, may be accumulated with its use and also depreciated or destroyed (Svendsen and Svendsen 2004).

The strength or weakness of the linkages of the individual or organization with other individuals and organizations is an important element related to social capital (Granovetter 1983). Both strong intra-community ties (among members of a family, an association, or an ethnic group of immigrants) and weak inter-community ties are necessary to guarantee the efficacy of social capital (Woolcock and Narayan 2000). Bonding social capital will derive from the strong intra-community ties and bridging social capital will derive from weak inter-community ties.

On the other hand, social capital has a multidimensional level (Grootaert and van Bastelaer 2001). First, the macro or social level focuses on the potential benefits for the society of individuals' and organizations' social networks, such as improved income levels (Fukuyama 1995; Knack and Keefer 1997; Dakhli and de Clerq 2004). Second, the micro or individual level focuses on the potential benefits of network relations for the person, such as the entrepreneurial start-up or firm success (Lin 2003; Davidsson and Honig 2003). Finally, the meso or organizational level focuses on the potential benefits of network relations for the organization, such as a higher efficiency (Putnam 1993).

Nevertheless, at the micro, meso and macro levels, the benefits obtained from both bonding and bridging social capital derive, in turn, from two other types of social capital: structural and cognitive (Uphoff 2000; Grootaert and van Bastelaer 2001). On the one hand, cognitive social capital derives from mental processes and resulting ideas, reinforced by culture and ideology, generating shared norms, values, attitudes, beliefs, and trust. Thus, cognitive social capital has a subjective and intangible character, contributing to cooperative behavior and stimulating collective action. On the other hand, structural social capital is related to several forms of social organization, particularly rules, procedures, and formal social networks, which also contribute to cooperation and, especially, to a collective action to obtain mutual benefits. However, unlike cognitive social capital, structural social capital is a relatively objective and externally observable construct.

In order to reformulate Ajzen's model, four different considerations regarding these aspects of social capital are made to help achieve the objectives of this paper. 
First, we are placed at the individual level of analysis and not at the meso- or macrosocial levels. This means that we should try to specify the influence of social capital on the individuals' perceptions regarding the configuration of their intentions to start-up. Second, the kind of social capital to be incorporated into entrepreneurial intention models will be cognitive rather than structural because intentions are previous to the performance of any specific behavior. Third, the origin of that cognitive social capital can emerge both from the close contact with relatives or friends (bonding cognitive social capital) and from sporadic contacts with other people or organizations in which the individual does not actively participate (bridging cognitive social capital). Finally, the specific location of social capital within the entrepreneurial intention model has to be carefully reconsidered. As social capital can be bonding or bridging, both types may exert a direct influence on perceived feasibility and desirability, and only then, indirectly, on intentions.

In this respect, bonding social capital based on strong ties from family or other close relationships may generate in the cognitive dimension different values, beliefs, or trust favoring individual perceptions. Thus, values assumed through contact with family or friend entrepreneurs would generate more favorable perceptions of desirability or feasibility to create a firm. On the other hand, bridging cognitive social capital, in spite of being based on weak ties, may also generate favorable values and beliefs towards a specific behavior, such as firm start-up. Therefore, it would be positively influencing perceived desirability and feasibility. This impact would increase when those weak ties derive from the individual's relationships with specific networks, such as entrepreneurial promotion agencies or entrepreneurial networks. Non-entrepreneurs may get in touch with these kinds of organizations in different ways. For instance, other persons may inform them of their existence and functions. Non-entrepreneurs may be also forced to establish direct contact with these organizations for different reasons: as part of their job in a firm or, perhaps, because of their work for one of these organizations. In this respect, it is quite evident that the different contacts and experiences acquired by a person could provide her/him with higher self-confidence so as to estimate becoming an entrepreneur as desirable and/or feasible.

After these previous considerations, a conceptual model including different variables of cognitive social capital and other cognitive factors of Ajzen's model has been elaborated with the objective of being tested in the empirical analysis of the paper (Fig. 1).

\section{Empirical Analysis}

The empirical analysis was carried out through a questionnaire given to a sample of young undergraduate students in the last year of their Economics and Management degrees. This kind of sample is very common in entrepreneurship studies (Krueger et al. 2000).

The sample was obtained from the two state universities in the metropolitan area of Seville, with more than 1.2 million inhabitants. It was made up of 354 students. The sample consisted of $69.2 \%$ Management students, and the remaining were Economics students. With regard to other demographic aspects, 55\% of interviewees 


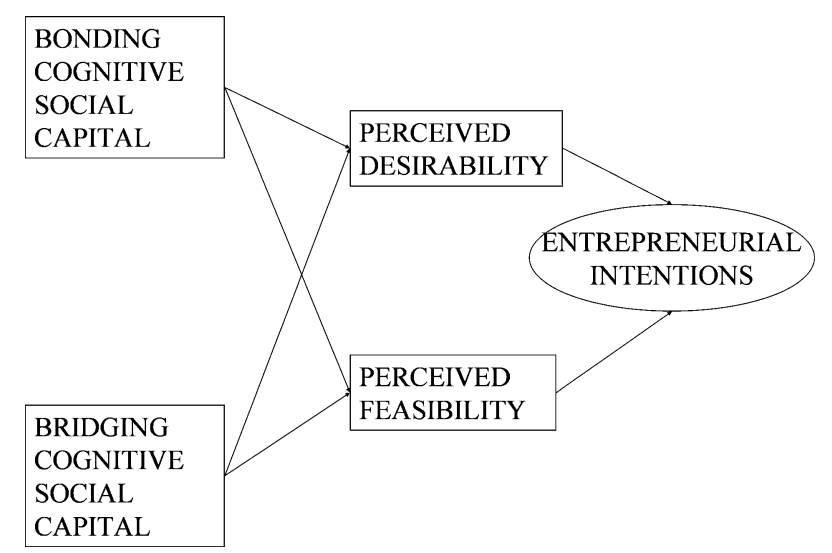

Fig. 1 Entrepreneurial intention model with cognitive social capital

were women, while the average age was 23.7 years old. These figures broadly correspond with the general characteristics of students of both degrees. Therefore, the sample may be considered as representative. Fieldwork was carried out during October and November of 2004.

The Entrepreneurial Intention Questionnaire (EIQ) used for the analysis has been carefully developed from the entrepreneurship literature (Krueger et al. 2000). Theoretical papers on the theory of planned behavior (Ajzen 1991, 2001) and on the theory of social capital (Woolcock and Narayan 2000; Uphoff 2000; Grootaert and van Bastelaer 2001) have also been developed.

For our empirical analysis, 33 specific indicators have been used. Sixteen of them correspond to measures of social capital, and the remaining ones have been used to measure the central elements of the entrepreneurial intention model. Likert-type scale was built into the EIQ to pick up the information and create the different indicators. On the other hand, with these sets of indicators, eight different constructs have been built: four for bonding cognitive social capital (approval for start-up in closer environment, knowing family entrepreneur, knowing non-family entrepreneur and valuation of the entrepreneurial option in the closer environment), one for bridging cognitive social capital (contact with entrepreneur environment), one for perceived desirability, one for perceived feasibility, and, finally, one for entrepreneurial intention.

Finally, to test the relationships between the different factors of the theoretical model, a multivariate analysis technique based on partial least squares (PLS) has been used. According to Gefen et al. (2000), when exploratory studies are carried out and a relatively small sample is used, this multivariate statistical technique is more suitable than others, such as LISREL, based on covariance analysis. The software used for this study has been PLSGraph V. 3.00 Build 1126 (Chin and Frye 2003). Nevertheless, before specifying the full empirical model and carrying out the regression analysis, a reliability test was carried out (Cronbach's $\alpha$ ).

In this sense, Table 1 offers the results of the reliability analysis for each one of the eight constructs. As may be observed, the values of this statistic are higher than 0.70 , the usual threshold recommended for newly created measures. Knowing non- 
Table 1 Reliability analysis (Cronbach's $\alpha$ )

\begin{tabular}{lll}
\hline Construct & Number of Indicators & Cronbach's $\alpha$ \\
\hline Entrepreneurial intention & 6 & 0.94 \\
Perceived feasibility & 6 & 0.89 \\
Perceived desirability & 5 & 0.91 \\
Contact with entrepr. Environment & 7 & 0.89 \\
Close approval of start-up & 3 & 0.76 \\
Close valuation & 2 & 0.72 \\
Family entrepreneur & 1 & - \\
Non-family entrepreneur & 3 & 0.27 \\
\hline
\end{tabular}

family entrepreneurs, with a value of 0.27 , is the only exception. This value indicates a low correlation among the three indicators making up this construct. From a logical point of view, knowing a friend entrepreneur does not necessarily imply knowing a different entrepreneur. This result will have to be taken into account when the structural model is specified.

Secondly, the detailed structural model specification is shown in Fig. 2. The model includes the expected influence of the four constructs measuring bonding social capital on perceived desirability and perceived feasibility. Similarly, the expected influence of the bridging social capital construct on perceived desirability and perceived feasibility has also been included. Finally, the influence of perceived desirability and perceived feasibility on the entrepreneurial intention is considered.

All the constructs, except one, have been defined as reflective. That is to say, each one of the indicators explaining the construct reflects an aspect of the latent concept

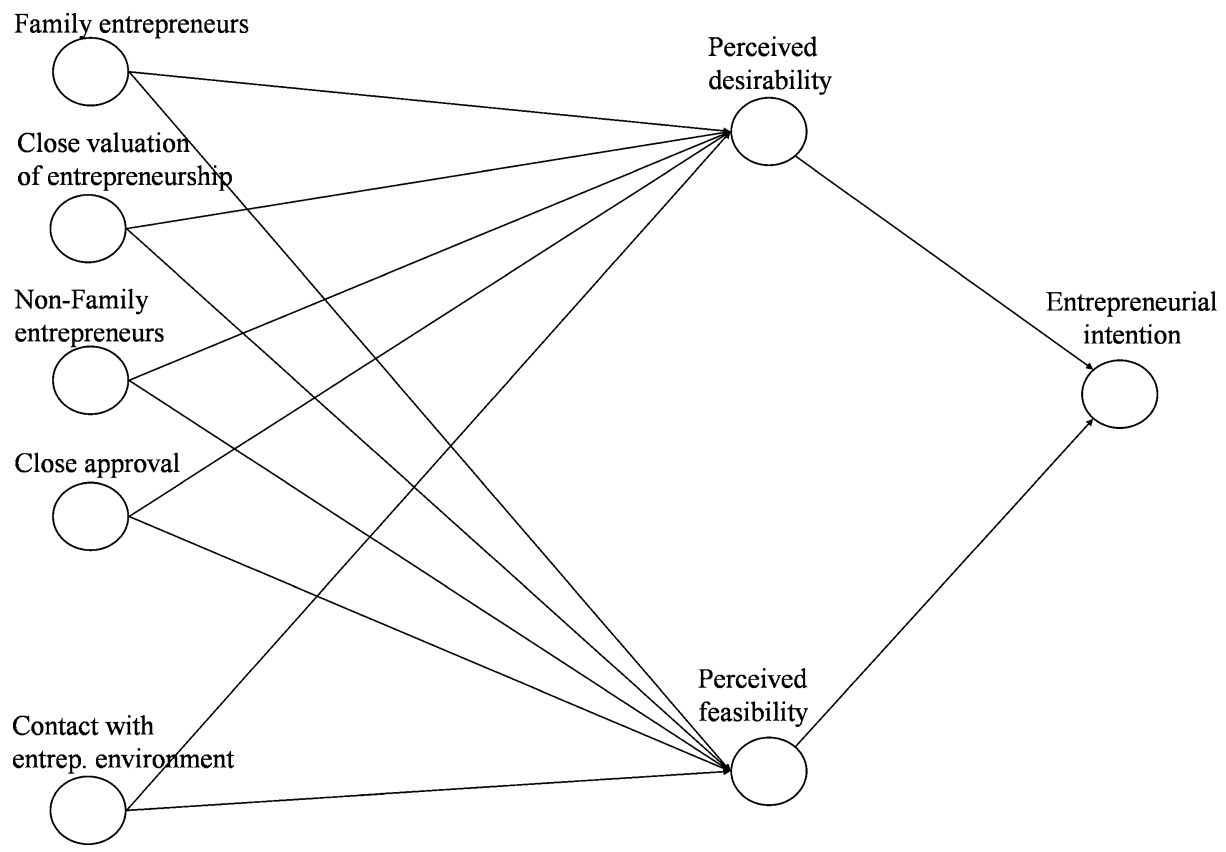

Fig. 2 Initial structural model 
(Roldán and Leal 2003). Therefore, a high correlation will be expected among the indicators themselves and between them and the latent construct. On the other hand, knowing non-family entrepreneurs has been defined as a formative construct. That is to say, the latent variable is formed as a combination of the values of the indicators which, then, do not have to be highly correlated among themselves or with the construct (Roldán and Leal 2003). This decision has been taken on the basis of the result of Cronbach's reliability test.

When the statistical significance of regression coefficients was studied, two of them were non-significant. For this reason, they were removed from the analysis. The final model results are presented in Fig. 3, where all the coefficients are significant. As may be observed, the proposed model explains $57 \%$ of the variance in entrepreneurial intention through the joint effect of perceived desirability and perceived feasibility. Moreover, the social capital variables alone explain $19.2 \%$ of the variance in perceived desirability and $16.8 \%$ of the variance in perceived feasibility.

Other results are the following:

a) The influence of bonding cognitive social capital on perceived desirability has been fully corroborated. However, the influence on perceived feasibility has only been partially confirmed, since just two of the four indicators (knowing non-family entrepreneurs and the perception that the close environment would approve of the decision to start up a firm) exert a significant influence on it.

b) The influence of bridging cognitive social capital on perceived feasibility has been corroborated. Nevertheless, the influence on perceived desirability has not been confirmed.

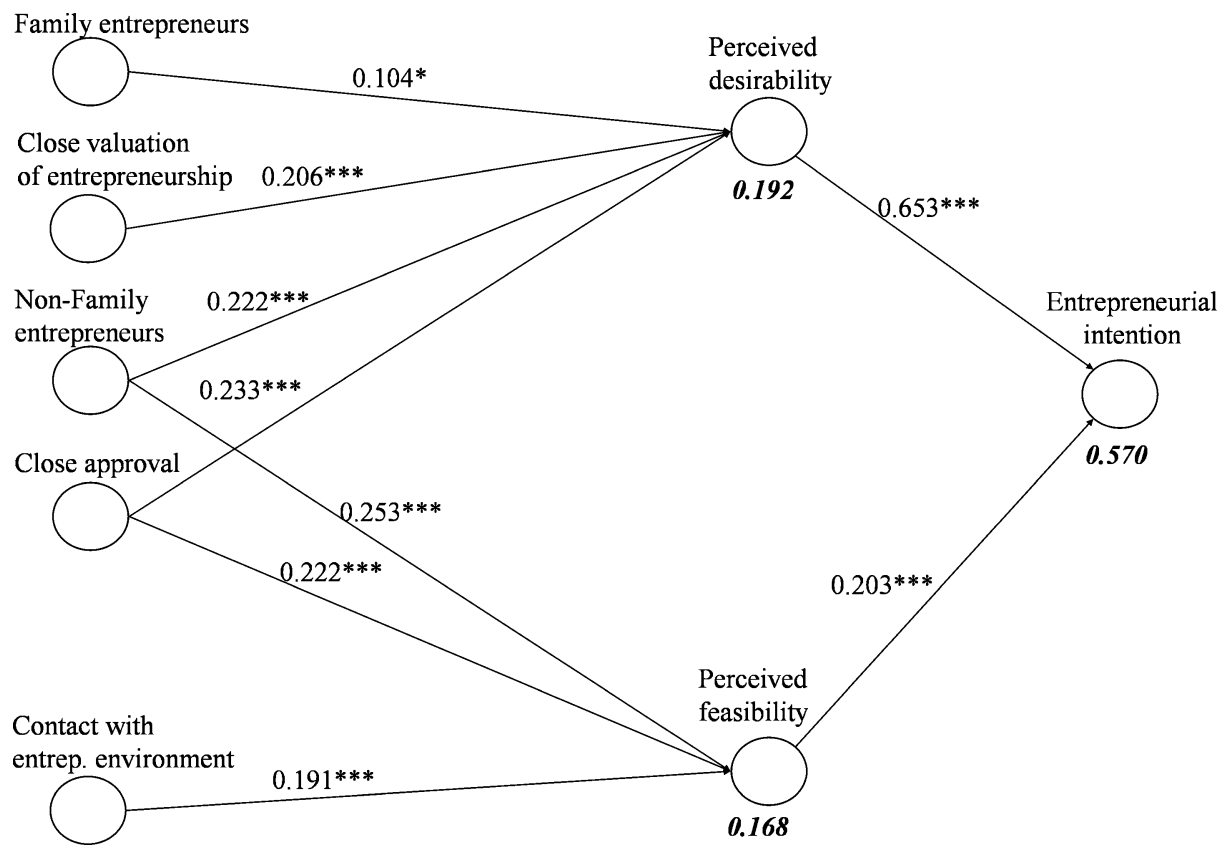

Fig. 3 Final structural model results. Note: ${ }^{*} p<0.05 ;{ }^{* *} p<0.01 ; * * * \mathrm{p}<0.001$

Springer 
c) The influence of perceived desirability and feasibility on intentions has been fully corroborated.

\section{Conclusions and Discussion}

Due to the importance attributed nowadays to the entrepreneurial capacity as a source of competitive advantage and economic development in the world of globalization, research focused on the analysis of the start-up process is becoming more and more necessary. In this paper, entrepreneurial intention models developed by Shapero and Sokol (1982) and Ajzen (1991) have been our starting point. They help to explain the cognitive factors influencing the intention to start a firm. However, social capital has been incorporated as a novel factor to those models. Social capital is the whole set of relationships individuals have. It offers access to other production resources, such as physical or human capital, and also facilitates decision-making processes and collective action through reciprocity and mutual trust.

In the theoretical model proposed, cognitive social capital has been specifically considered, since it transmits values, beliefs, and attitudes through the individuals' relationships, determining perceptions and, therefore, intentions to start a firm. The sources of this cognitive social capital considered have been, specifically, twofold: derived from the individual's strong ties (bonding social capital) and derived from the individual's weak ties (bridging social capital).

In the empirical analysis carried out on a sample of potential entrepreneurs, the influence of some cognitive social capital factors and perceptions on the intention to start a firm have been studied. The constructs for measuring cognitive social capital exert their influence first on perceptions and these, in turn, on intentions. The proposed structural model explains $57 \%$ of the variance in entrepreneurial intention. We previously tested the model for the existence of direct social capital-intention relations, and none of them was significant Therefore, results have confirmed the existence of an indirect influence of the constructs defining cognitive social capital on the entrepreneurial intention.

From the different relationships hypothesized in the theoretical model, only one has been rejected, whereas another has been partially confirmed. In this second case, it seems from the results that the relationships of bonding cognitive social capital with perceived feasibility is relatively weak. In fact, knowing family entrepreneurs would be stimulating only the desire but not the confidence in the individual's own capacities. However, it is interesting to note that non-family entrepreneurial rolemodels are those exerting the highest influence on feasibility.

Similarly, it is also interesting to distinguish the influence exerted on perceptions by the other two bonding cognitive social capital constructs: valuation of the entrepreneurial option in the closer environment, and approval of the decision to start a firm. If the entrepreneurial career is positively valued in the closer environment, the desire to become an entrepreneur is higher, but not the feasibility perceptions. Meanwhile, if individuals feel the idea to start the firm is approved in 
that closer environment, they will also feel more capable. It seems individuals are aware of the need for support to create the firm. Thus, this approval makes them feel that they can count on that support.

Regarding the construct used to measure bridging social capital (contacts with entrepreneurial networks and start-up support bodies), it only influences feasibility, but not desirability. This could be due to the special nature of this kind of social capital. It may not transmit values. Rather, it would generate trust through increased knowledge of the entrepreneurial activity and the way to obtain some support when difficult problems arise. Thus, bridging social capital would contribute to increasing feasibility perceptions.

Regarding the significant influence on intention from the desirability and feasibility constructs, the results obtained are similar to those found in previous empirical research. Therefore, the robustness of the entrepreneurial intention model would be reinforced.

Nevertheless, it has to be acknowledged that this is only a first step in the analysis of the cognitive social-capital role on entrepreneurial intentions. There is, therefore, much to be done in this field. On the one hand, it would be necessary to clarify which specific values from the closer environment are transmitted to the individual and how the transmission takes place. On the other hand, it is also important to increase our knowledge of the type of elements reinforcing trust and self-confidence when an individual gets in touch with entrepreneurial networks or entrepreneurial promotion institutions. Finally, new and better constructs to measure social capital, either bonding or bridging, are needed. In this way, clearer results would be obtained, and a better understanding about their effects on entrepreneurial intention would be gained.

Acknowledgments We are most grateful to the participant of the session of entrepreneurship, and especially to the chair Miguel A. Galindo, for their interesting and helpful comments. We also thank W. Chin for his permission to use the PLSGraph software in the empirical analysis.

\section{References}

Ajzen, I. (1991). The theory of planned behavior. Organizational Behavior and Human Decision Processes, 50, 179-211.

Ajzen, I. (2001). Nature and operation of attitudes. Annual Review of Psychology, 52, $27-58$.

Audretsch, D. B., \& Thurik, A. R. (2000). Capitalism and democracy in the 21st century: From the managed to the entrepreneurial economy. Journal of Evolutionary Economics, 10, 17-34.

Bandura, A. (1977). Social learning theory. Englewood Cliffs, NJ: Prentice-Hall.

Barros, C. P., \& Alves, F. M. (2003). Human capital theory and social capital theory on sports management. International Advances in Economic Research, 9(3), 218-226.

Becker, G. S. (1964). Human capital. Chicago: University of Chicago Press.

Borland, C. M. (1975). Locus of control, need for achievement and entrepreneurship. Austin: The University of Texas.

Chell, E. (1986). The entrepreneurial personality: A review and some theoretical developments. In J. Curram, J. Stanworth, \& D. Watking (Eds.), The survival of the small firm. The economics of survival and entrepreneurship (vol. 1, pp. 102-119). Cambridge: Cambridge University Press.

Chin, W., \& Frye, T. (2003). PLS Graph V.3.00 (Build 1126). Houston: University of Houston.

Coleman, J. S. (1988). Social capital in the creation of human capital. The American Journal of Sociology, 94, 95-120.

Springer 
Dakhli, M., \& de Clercq, D. (2004). Human capital, social capital and innovation: A multicountry study. Entrepreneurship and Regional Development, 16, 107-128.

Davidsson, P. (1991). Continued entrepreneurship: Ability, need and opportunity as determinants of small firm growth. Journal of Business Venturing, 6, 405-429.

Davidsson, P., \& Honig, B. (2003) The role of social and human capital among nascent entrepreneurs. Journal of Business Venturing, 18, 301-331.

Fukuyama, F. (1995). Trust: The social virtues and the creation of prosperity. New York: The Free Press.

Galindo, M. A., \& Alvarez, A. (2004). Human capital and economic growth in Spanish regions. International Advances in Economic Research, 10(4), 257-264.

Gefen, D., Straub, D. W., \& Boudreau, M. C. (2000). Structural equation modelling and regression: Guidelines for research practice. Communications of the Association for Information Society, 4(7), 1-77.

Granovetter, M. (1983). The strength of weak ties: a network theory revisited. Sociological Theory, 1, 201-233.

Grootaert, C., \& van Bastelaer, T. (2001). Understanding and measuring social capital: A synthesis of findings and recommendations from the social capital initiative. The World Bank, Social Capital Initiative, Working paper no. 24.

Knack, S., \& Keefer, P. (1997). Does social capital have an economic payoff? A cross-country investigation. The Quarterly Journal of Economics, 112(4), 1251-1288.

Krueger, N. F., \& Carsrud, A. L. (1993). Entrepreneurial intentions: Applying the theory of planned behavior. Entrepreneurship and Regional Development, 5, 315-330.

Krueger, N. F., Reilly, M. D., \& Carsrud, A. L. (2000). Competing models of entrepreneurial intentions. Journal of Business Venturing, 15(5/6), 411-432.

Lin, N. (2003). Social capital, a theory of social structure and action. Cambridge: Cambridge University Press.

Liñán, F. (2004). Intention-based models of entrepreneurship education. Piccolla Impresa/Small Business, $3,11-35$.

Lumpkin, G. T., \& Dess, G. G. (1996). Clarifying the entrepreneurial orientation construct and linking it to performance. Academy of Management Review, 21(1), 135-172.

Putnam, R. D. (1993). Making democracy work: Civic tradition in modern Italy. Princeton: Princeton University Press.

Reynolds, P. D., Hay, W. M., \& Camp, S. M. (1999). Global entrepreneurship monitor 1999, executive report. London: London Business School \& Babson College.

Reynolds, P., Storey, D. J., \& Westhead, P. (1994). Cross-national comparison of the variation in new firm rates. Regional Studies, 28, 443-456.

Roldán, J. L., \& Leal, A. (2003). A validation test of an adaptation of the DeLone \& McLean's model in the Spanish EIS field". In J. J. Cano (Ed.), Critical reflections on information systems. A systematic approach (pp. 66-84). Hershey, PA: Idea Group Publishing.

Santos, F. J., \& Guzmán (2001). The booster function and the entrepreneurial quality: An application to the province of Seville. Entrepreneurship and Regional Development, 13, 211-228.

Shapero, A., \& Sokol, L. (1982) Social dimensions of entrepreneurship. In C. A. Kent, D. L. Sexton, \& K. H. Vesper (Eds.), Encyclopaedia of entrepreneurship. Englewood Cliffs, NJ: Prentice Hall.

Svendsen, G. L. H., \& Svendsen, G. T. (2004). The creation and destruction of social capital: Entrepreneurship, co-operative movements and institutions. Cheltenham: Edward Elgar.

Uphoff, N. (2000). Understanding social capital: Learning from the analysis and experience of participation. In P. Dasgupta \& I. Serageldin (Eds), Social capital, a multifaceted perspective (pp. 215-249). Washington: The World Bank.

Wennekers, S., \& Thurik, R. (1999). Linking entrepreneurship and economic growth. Small Business Economics, 13, 27-55.

Woolcock, M., \& Narayan, D. (2000). Social capital: Implications for development theory, research and policy. The World Bank Research Observer, 15(2), 225-249. 